\title{
An experimental study of the effect of water bodies temperature on water heat pump performance
}

\author{
Amer Saloum ${ }^{1, *}$, and Vyacheslav I. Maksimov ${ }^{1}$ \\ ${ }^{1}$ National Research Tomsk Polytechnic University, 634050 Tomsk, Russia
}

\begin{abstract}
The purpose of this research is to study the effect of water temperature change in the reservoir on water heat pump performance. An experimental analyse is done on the heat pump station which depends on water as a heat source. The experimental results confirm that the ice formation has a negative effect on the heat exchange efficiency, and the increase in water source temperature slow down the ice formation rate which causes an appositive effect on the system performance.
\end{abstract}

\section{Introduction}

Traditional heating systems are the basic source of pollution, that's why the use of heat pumps grows nowadays. The heat pumps depend on the water-air-and ground as an energy source. the heat pump which depends on water as the energy source (rivers-lakes-sea water) is a promising technology because even when the air temperature drops to $-5{ }^{\circ} \mathrm{C}$ in many areas in the world, the water surfaces temperatures keep in the range (7-13) ${ }^{\circ} \mathrm{C}$. There is a lack of information about water source heat pump systems.

The thermodynamic analysis shows that the temperature of the heat source has the highest effect on the heat pump performance, the heating time for water in condenser and the ice formation characteristics. The velocity of ice formation ratio on the evaporator tube has a high effect on the system performance and heat exchange rate between the Freon and water in the evaporator.

\section{Experimental setup and study technique}

An experimental study is done to analyze the influence of water surface temperature on heat pump performance. The experimental method is explained in [4], But in these experiments 15 thermocouples are fixed in the water reservoir with step $1.53 \mathrm{~cm}$ by height between every two thermocouples to measure the change in water temperature around the evaporator and condenser, and 15 thermocouples were fixed along the evaporator and condenser tube as shown in Table 1 and Fig. 1.

\footnotetext{
Corresponding author: amer-salom@hotmail.com
} 
Table 1. Thermocouples location along the heat exchanger pipes.

\begin{tabular}{|c|c|c|c|c|c|c|c|c|c|c|c|c|c|c|c|}
\hline$*$ & 1 & 2 & 3 & 4 & 5 & 6 & 7 & 8 & 9 & 10 & 11 & 12 & 13 & 14 & 15 \\
\hline $\begin{array}{l}\Xi \\
\check{x}\end{array}$ & 0 & $\overrightarrow{0}$ & $\begin{array}{l}\frac{2}{0} \\
0 \\
0\end{array}$ & $\stackrel{0}{0}$ & $\overrightarrow{0}$ & $\begin{array}{l}\frac{n}{0} \\
\stackrel{0}{0}\end{array}$ & $\stackrel{\overbrace{}}{0}$ & $\overrightarrow{0}$ & $\begin{array}{l}n \\
0 \\
0 \\
0 \\
1\end{array}$ & $\begin{array}{l}n \\
\text { है } \\
0\end{array}$ & $\begin{array}{l}n \\
\infty \\
0 \\
0\end{array}$ & $\begin{array}{l}n \\
0 \\
0 \\
0 \\
1\end{array}$ & $\stackrel{\infty}{\circ}$ & $\begin{array}{l}n \\
\tilde{c} \\
0\end{array}$ & 0 \\
\hline$\lambda$ & 0 & $\stackrel{2}{\mathscr{8}}$ & $\stackrel{2}{\stackrel{2}{0}}$ & 0 & $\frac{i n}{\stackrel{0}{0}}$ & $\overrightarrow{0}$ & 0 & $\frac{n}{ \pm}$ & $\overrightarrow{0}$ & 0 & $\frac{n}{ \pm}$ & $\frac{n}{0}$ & 0 & $\frac{17}{ \pm}$ & $\stackrel{n}{0}$ \\
\hline$N$ & $\stackrel{\sigma}{0}$ & $\stackrel{n}{\stackrel{2}{0}}$ & $\stackrel{n}{0}$ & $\stackrel{\circ}{\circ}$ & $\stackrel{\circ}{0}$ & $\stackrel{\circ}{\circ}$ & $\stackrel{n}{m}$ & $\frac{n}{\infty}$ & $\frac{n}{\stackrel{n}{0}}$ & $\stackrel{\infty}{\stackrel{0}{0}}$ & $\frac{\infty}{0}$ & $\frac{\infty}{0}$ & 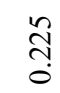 & 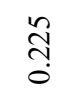 & $\stackrel{\text { O̊ }}{0}$ \\
\hline
\end{tabular}

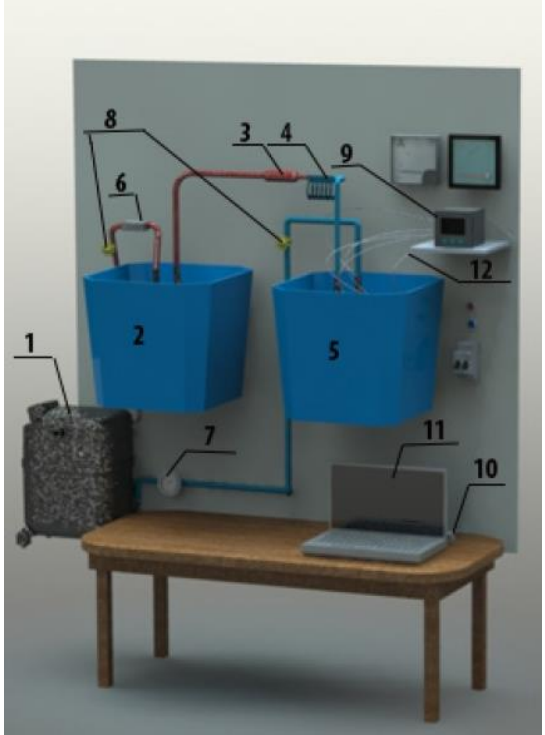

(a)

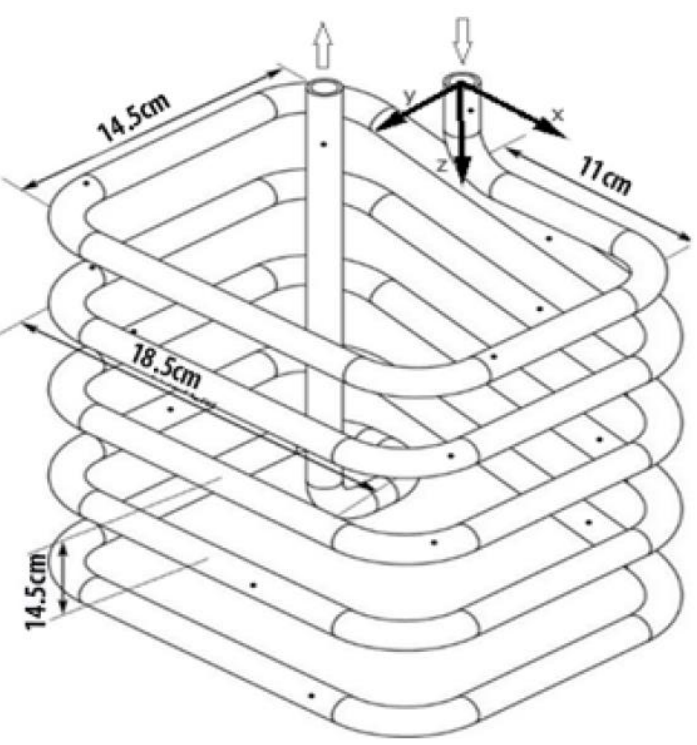

(b)

Fig. 1. (a) Schematic diagram of the experimental setup: (1) compressor, (2) condenser, (3) desiccant, (4) capillary tube, (5) the evaporator, (6) flowmeter, (7) Manometer, (8) valve, (9) Analog-to-digital converter, (10) the network adapter, (11) the computer, (12) thermocouples; (b) Tubes of the heat exchanger(evaporator-condenser). The points represent the thermocouple locations.

\section{Experimental results}

The initial drop in Freon temperature, is the same for both cases when start water reservoir temperature $7{ }^{\circ} \mathrm{C}\left(-15^{\circ} \mathrm{C}\right)$ and the case when it is $13{ }^{\circ} \mathrm{C}$, that means that the drop-in water temperature in the reservoir does not affect the Freon temperature in the tubes. The initial increase in the system efficiency Fig. 2 is explained by the sharp decrease in freon temperature in evaporator because according to thermodynamics the drop in Freon temperature in the evaporator leads to increase in system efficiency. 


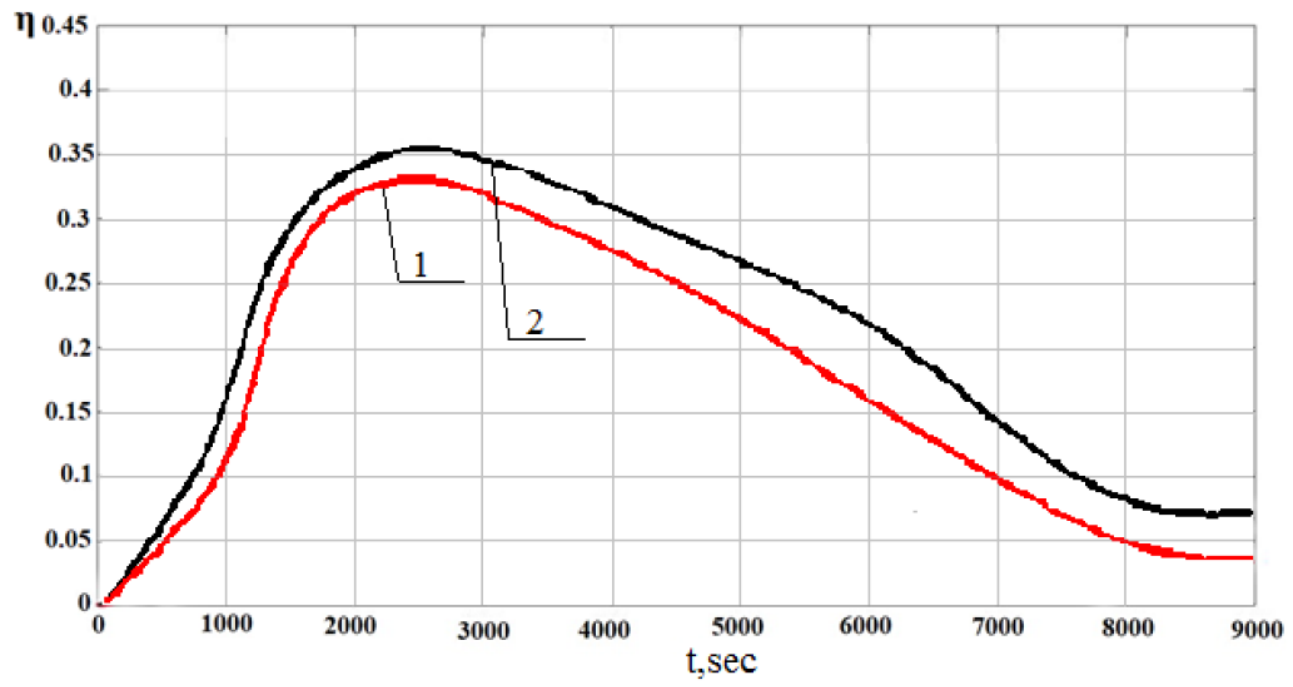

Fig. 2. Changes in the coefficient of cooling with time. 1 - For the case where the initial temperature is $280 \mathrm{~K} .2$ - For the case when the initial temperature is $+13{ }^{\circ} \mathrm{C}$.

The water temperature does not fall down the value $+4{ }^{\circ} \mathrm{C}$ for the studied time, when the initial water temperature is $13{ }^{\circ} \mathrm{C}$, but this temperature drops to the value $+2{ }^{\circ} \mathrm{C}$ in case, the initial water temperature is $7{ }^{\circ} \mathrm{C}$ and the water behavior change like it was explained in [4], but how to answer the question if the drop in Freon temperature is the same why the system efficiency is less, this is caused by ice formation rate, because the ice reduces the efficiency of heat exchange, and the ice layer on the evaporator tube is thicker for the first case as can be seen in Fig. 3 and Fig. 4 (the maximum ice thickness for the first case is more than $10 \mathrm{~mm}$ where it is less than $7 \mathrm{~mm}$ for the second case.

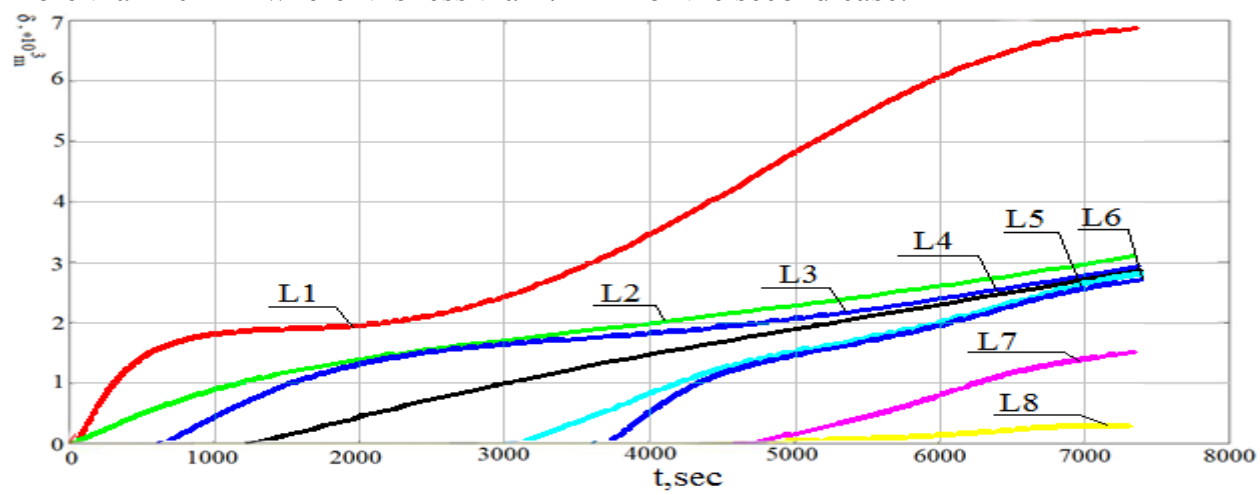

Fig. 3. Ice thickness change with time in different locations along the evaporator tube (in the case where the water initial temperature is $+7{ }^{\circ} \mathrm{C} \mathrm{K}$ in the reservoir around the evaporator). (L1..L8) the distances for the start point of the evaporator which are shown in Table.2.

Table 2. The location of measuring points for ice thickness along the evaporator pipe.

\begin{tabular}{|c|c|c|c|c|c|c|c|c|c|}
\hline \multicolumn{2}{|c|}{} & L1 & L2 & L3 & L4 & L5 & L6 & L7 & L8 \\
\hline \multicolumn{2}{|c|}{ m } & 0 & 0.115 & 0.26 & 0.445 & 0.59 & 0.775 & 0.92 & 0.1105 \\
\hline \multirow{2}{*}{$\begin{array}{c}\text { Cartesian } \\
\text { coordinates }\end{array}$} & $\mathrm{x}$ & 0 & 0.115 & 0.115 & -0.07 & -0.07 & 0.115 & 0.115 & -0.07 \\
\cline { 2 - 10 } & $\mathrm{y}$ & 0 & 0 & 0.145 & 0.145 & 0 & 0 & 0.145 & 0.145 \\
\cline { 2 - 10 } & $\mathrm{z}$ & 0 & 0.045 & 0.045 & 0.045 & 0.045 & 0.09 & 0.09 & 0.09 \\
\hline
\end{tabular}




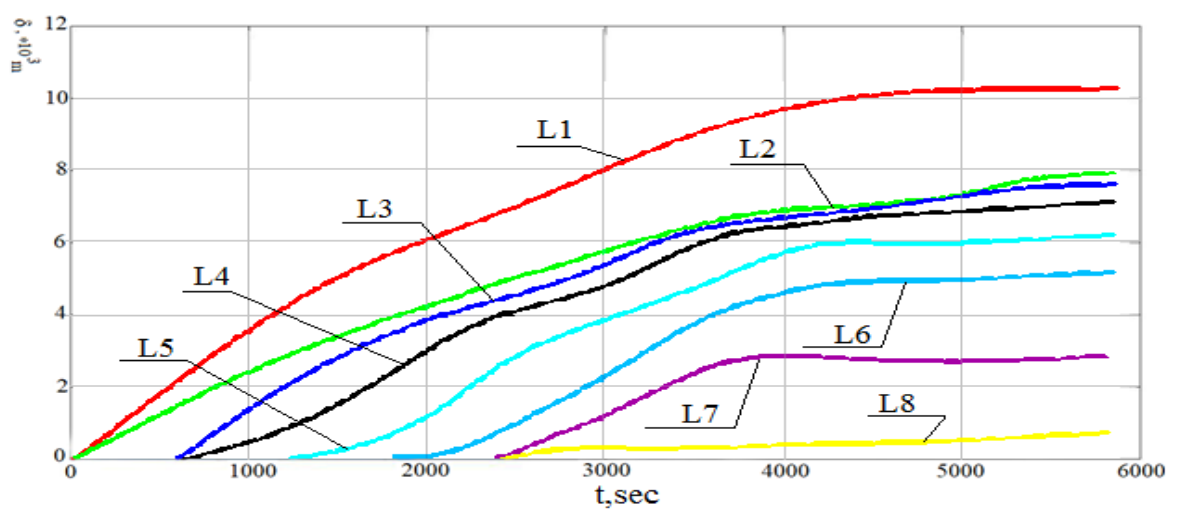

Fig. 4. Ice thickness change with time at different locations along the evaporator tube (in the case where the water initial temperature is $+13{ }^{\circ} \mathrm{C}$ in the reservoir around the evaporator). (L1...L8) the distances for the start point of the evaporator which are shown in Table 2.

\section{Conclusion}

The experimental results show that the Freon temperature in the heat pump system, does not change when the temperature of the water in reservoir is less, but the ice growth rate on the evaporator pipe is higher, and thicker layer of ice in the range $5 \%$ for every $1{ }^{\circ} \mathrm{C}$, the existence of ice layer on the evaporator tube reduced the heat exchange efficiency and the system efficiency to collect energy from the water is reduced to $1.4 \%$ for every $1{ }^{\circ} \mathrm{C}$.

It must be pointed out that the experiment is done with the use of the same capillary tube, which affect the drop in the Freon temperature and pressure, in the next research the effect of the enthalpy on the entry of the capillary tube on the system performance must be studied to choose the best dimensions for this tube which are compatible with the system working conditions.

The results of this research can be used to assess the water heat pump work under the conditions of ice formation, in different conditions of water source temperatures, and how that affects the system efficiency.

\section{References}

1. S. Zou, X. Xie, Appl. Therm. Eng. 7, 200 (2016)

2. A.C. Morton, Assessing the performance of a reservoir-based water source heat pump (Strathclyde university, Glasgow, 2013)

3. Y. Wang, Analysis on the practical use of open-loop surface water source heat pump systems (SWHP)( Chongqing University, Oklahoma, 2011)

4. V.I. Maksimov, A. Saloum, MATEC Web Conf. 110, 01074 (2017)

5. L. Schibuola, Massimiliano Scarpa Energy and Buildings, 6, 182 (2015)

6. N.V. Demyanovich, V. I. Maksimov, T.A. Nagornova, MATEC Web Conf. 92, 01067 (2017)

7. G.P.Vasilyeva, N.V. Peskova, V.F. Gornova, M.V. Kolesova, Geothermics 10, 93 (2016)

8. T.A. Kawalecki, A. Cybulski, Polish Academy of Science 10 (1995)

9. V.I. Maksimov, T.A. Nagornova, V.S. Chernyshev, MATEC Web Conf. 23, 01051 (2015) 